\title{
CIRCULAR CITY: A METHODOLOGICAL APPROACH FOR SUSTAINABLE DISTRICTS AND COMMUNITIES
}

\author{
ANDREA BOERI, JACOPO GASPARI, VALENTINA GIANFRATE, \\ DANILA LONGO \& SAVERIA O. M. BOULANGER \\ Department of Architecture, University of Bologna, Italy
}

\begin{abstract}
The increasing complexity of urban growth strongly impacts both on the quality of urban environment and on the effectiveness of models for development, requiring innovative approaches to face the related challenges. The proposed position paper reports the methodological approach outlined within a trans-European research project. It aims at defining a systemic urban vision based on resource loops vision in a clustered perspective, overcoming the conventional separation between urban and periurban areas. The main scope is to drive a transition from a linear ("take-make-use-dispose") to a circular approach, considering the whole city realm and aiming to close resource loops (in line with EU COM 614/2015, Closing the loop, EU COM 33/2017, Implementation of the Circular Economy Action Plan and Urban Agenda Draft Action Plan on Circular Economy 09.02.2018) while generating new market opportunities and jobs, reducing resources import, decreasing impacts on environment and climate change. The methodology includes the following steps: increasing context understanding, identifying resource flows, using economic potential of existing resources, engaging communities in loops of proximity, facilitating entrepreneur and stakeholders in co-creation of circular economy processes. This paper explains the positioning of the research within the state of the art; it describes the applied methodology and related expected outcomes, defines the main related initiatives and implementation models. This study identifies regenerative corridors (RC) as potential effective drivers to overcome the conventional separation between urban, peri-urban and rural areas in the EU context, investigating their relations and identifying driving factors for a circular equalized development among these different urban zones. This paper also reports on the impact indicators and the replication potential of the proposed systemic approach.

Keywords: circular city, regenerative city, urban corridors, systemic approach, urban scenario, closing loops, resources, urban metabolism.
\end{abstract}

\section{INTRODUCTION}

During the last years, the idea of "Circular City" is emerging in the scientific literature as an interesting field of debate fed by a number of open challenges that the cities of tomorrow will be facing: scarcity of resources, economic crisis, lack of social identity, innovation and availability of technologies. However, the topic is far from having achieved clearly defined boundaries especially when case studies meet the real context conditions. Thus, the topic is evolving according to a turning point of the transition period most of contemporary cities are experiencing [1]-[4]. As stated many times by the EU in the last few year's [5]-[7], cities can be defined as the keystones of the European well-being for economic strength, wealth and social opportunities for the future. The population growth is indeed increasing the urban density year-by-year, feeding a complex interaction of parameters dealing with urban management and sustainability. Waste management, energy demand peak, traffic congestion, air and water pollution, lack of identity, fuel poverty are some of the main problems challenging the city authorities in a long-term perspective [8], [9]. Among them, some specific recurring elements, creating the context and background for suitable solutions are of particular interest for this research: 
- the acknowledgement of the European decrees - 2010/31/EU [10] - imposing a substantial reduction of emissions (20\% before 2020 and $40 \%$ before 2030 ) and an overall improvement of environmental conditions and urban energy savings;

- the pressure of the global market that continuously proposes new ICT technologies and devices to enable citizens' connection to services and tools;

- the great amount of existing buildings and neighbourhoods affected by obsolescence phenomena related to energy demand, indoor/outdoor quality, resource management, fuel poverty;

- the lack of long term planning visions to tackle the urban sprawl;

- the constant growth of land use and the related effects on urban climate conditions;

- the constant rise of resources demand connected with population growth;

- the digital revolution linked to social networks that may produce unpredictable effects on social relations and behaviours as well as on the use of urban spaces [11].

Mitigation and adaptation measures to climate changes as well as new ways for resource management are addressed, in the scientific literature [7], [8], [11]-[13], as some of the most challenging and urgent issues to support the transition toward low-carbon cities assuming that the urban metabolism is quickly approaching a point of no-return.

Hence, cities represent an important field to experiment sustainable and resilient solutions based on innovative technologies and enablers (both ICT or not), becoming the core of the debate about technological implementation, resource management and urban evolution.

The present work deals with the need to find new stripes for circular resource management and the definition of a new design strategy for regenerating the existing built environment in a more sustainable, resilient and smart perspective.

\section{ANALYSIS OF URBAN CIRCULAR APPROACHES BEYOND THE STATE OF THE ART}

According to a qualitative literature analysis, the concept of "circular city" started to be associated with products development, monopolistic competition and industrial organization [14] at the end of the last century, in contrast with the linear city model proposed by Hotteling [15]. At the beginning of the century, it was associated to different ways of planning cities: from ecology, to transport field, energy production and management and to people involvement into governance processes.

Only in recent times, the concept of circular city is associated with resource flows and management in cities, identifying a way of use and re-use resources [16] connecting the concept of urban environment with the idea of circular metabolism. This new approach overcame the "take-make-dispose" paradigm addressing the priority to re-use.

According to Kennedy et al. [17], urban metabolism can be defined as "the sum total of the technical and socioeconomic processes that occur in cities, resulting in growth, production of energy, and elimination of waste". In this framework, the circular city is strictly linked with the concept of "zero-waste city", becoming one of its synonym [18]. According to Zaman and Lehmann [18], the majority of actual cities propose a linear metabolism: resources are produced, used and finally disposed (as solid waste, wastewater or emissions to the atmosphere). While, "in a zero-waste city material flow is circular, which means the same materials are used again and again until the optimum level of consumption. No materials are wasted or underused in circular cities" [18]. This reflection led the concept of circular city becoming more and more strictly associated with the 
concept of circular economy. According to Kirchherr et al. [19], these issues are mainly related to reducing, reusing, recycling and recovering activities (4R) in cities even if "it is oftentimes not highlighted that circular economy necessitates a systemic shift". However, in the same research, it is highlighted how the impacts of circular economy are often linked with economic prosperity and less with sustainable development.

The study presented in this paper aims to go beyond the economic understanding of the topic assuming a systemic perspective that combines several aspects: circular economy and urban metabolism creating new interactions level including a plurality of stakeholders and transforming users in prosumers; including not only resources but also culture and society; creating a circular governance structure able to start from pilot intervention to their analysis of impact and replication in other contexts. Within this perspective, a circular city is not only a resource matter but a more comprehensive approach permeating all levels of the urban system.

\section{METHODOLOGY OF RESEARCH AND MODEL APPROACH}

The model is based on a multi-disciplinary and circular approach for the transition of urban and peri-urban areas toward regenerative cities: cities able to consider their impacts on the environment and the society while regenerating resources in a resilient perspective [20], [21]. Therefore, the proposed systemic model strengthens the relations among actions, actors, spaces and resources and it can act as an engine able to regenerate and to improve the mutual exchange between different areas of the cities.

The research group of the Department of Architecture - University of Bologna is studying this approach, expanding a model developed for historic city centres under the umbrella of "ROCK project" - Regeneration and Optimization of cultural heritage in Creative and Knowledge cities (EU-Horizon 2020 funded project; G.A. 730280). In ROCK project a circular model has been proposed and applied in several European cities with the aim of finding new ways for valorise cultural heritage while preserving its integrity and symbolic force. However, several topics can be addressed through a comprehensive circular methodology.

The model approach is based on integrating two interlinked concepts: the creation of resilience corridors able to connect different parts of the city (urban and peri-urban; historic downtown and peripheral areas, etc.; the economic centres to the satellite areas) and the creation of innovation hubs, nodes of innovation where specific actions can take place. The objective of the proposed methodology is to guide the transition towards the creation of regenerative cities, as defined by UN Habitat: "cities designed to be resilient by being energy efficient, low-carbon, and increasingly reliant on renewable energy sources, taking care of resources, recycling and reusing waste, using water, land, and energy in a coordinated manner and in harmony with its surrounding hinterland in support of urban and peri-urban agriculture" [21]. Furthermore, the model aims to enhance the process of regenerative cities by including multi-layered approaching and monitoring targeted to balance resources, energy, people flows, built environment, communities in a mix able to improve the presence of life quality, smartness and sustainability. It aims to develop an integrated approach that goes beyond the closing of resource loops, as defined by the EU COM 614 [22], to meet a deeper urban metabolism, where resource, energy and technological flows are balanced with a social approach based on the development of local ecosystems of stakeholders, innovative enterprises and integrated value chains. The two main aspects of this approach are: 
1. the development of linkages, interconnectivity and interdependencies in urban systems (energy, water and food and material provisioning systems);

2. the need for integrated holistic approaches across these sectors recognizes the linkages and aims to better respond to the need for integrated policies and implementation mechanisms with systems optimization through an approach to counter silo-thinking between the urban sectors, transforming the inefficient system and moving away from out-dated single-purpose solutions.

The aim is to support the shift of urban metabolism from its current wasteful linear system into a resource-efficient circular system. Yet creating a circular urban model implies connecting "systems" that were initially separated by technical, organizational and institutional solutions and changes ("multiple innovation processes"), to be adopted and adapted [23].

It's very important in the regeneration processes to overcome the "silos" approach and to connect the different systems involved or related to these processes. The model starts from the identification of the specific local systems articulated into:

- System of actors, as defined in the lists of Ecosystems of Stakeholders to list and prioritize the transformation needs, the collaboration pathways, the opportunity creation;

- System of places, starting from pilot areas and understanding their relations with the whole urban contexts, circulating solutions, tools, strategies and results of experimentation, to foster the replication of the most effective ones in similar contexts;

- System of initiatives (bottom-up and top-down; collaboration, sponsorship, partnerships, etc.) to promote creativeness and cultural production from different sources, combining them in common projects of regeneration;

- Systems of resources (physical resources, financial resources, human capitals) to promote a circulation of flows, overpassing the linear processes in the circular city, from extraction to waste, replacing them by circular processes and that lasting connections can be made between flows. These flows - such as goods, people, food, waste, water, wildlife and air - are the city's metabolism that allows the city and the economy to function.

Given these considerations, the model is based on a circular step-by-step approach, made of eight complementary phases of application (Fig. 1).

Phase 1 Analysis of the context. The context is investigated according to a multiple set of different aspects (resources, people, energy, environmental conditions, economy, etc.) to which properly identified KPI are related. The aim and the major output of this phase is the creation of an ID card of the Resilient Corridor and a first GIS-based database for the further development of scenarios.

Phase 2 Identification of the circular innovation nodes. This phase aims to define the location and the nature of the specific sites where pilot actions can firstly take place within the corridor.

Phase 3 Set a local ecosystem. Innovation hubs inside the resilient corridor are based on the creation of local ecosystem of stakeholders. Involving the major players of local communities with relation to needs and on-going activities at local and city level is a crucial action to deliver a modal shift. 


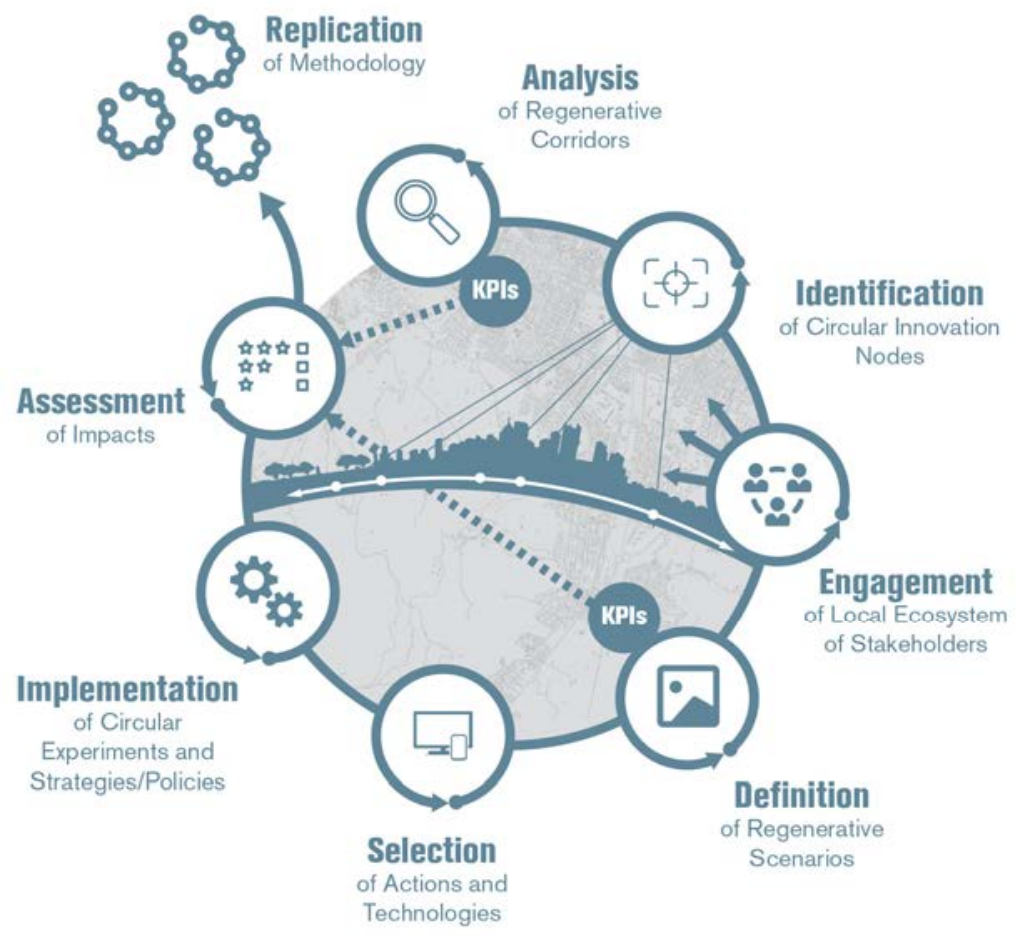

Figure 1: Model steps.

Phase 4 Scenarios generation and value chain proposition. According to the understanding of the local context given by phase 1 and 2 different scenarios can be simulated on an action-based perspective. Thus, scenarios can be drafted changing different sets of actions on the same timeframe in order to understand which set is able to optimize synergies and impacts with relation to the expected results.

Phase 5 Technological solutions and implementation plan definition. This phase is aimed to define which specific actions can be implemented in the first pilot application and which ones can be applied in further phases.

Phase 6 Implementation of actions and experiments. This phase is intended as the real application of selected actions.

Phases 7 and 8 Evaluation and replication. The delivery of the process is accurately evaluated both during preparation and implementation according to specific indicators in the entire demonstrator and at the same time observer cities are involved in assessing the replicability potential.

\section{RESILIENT CORRIDORS AND INNOVATION HUBS AS FIELDS OF APPLICATION}

The proposed model foresees the implementation of different actions, according to the following scheme: 
- Actions inside innovation hubs. aiming to collaborate with the already existing activities, the model will implement within the innovation hubs a panel of actions and technologies to enhance the potentialities given by urban metabolism and close the loops inside each ring with an impact on the whole area. The choice to work with already existing nodes of activity ensures the access to local stakeholders and community and the sustainability in the long-term perspective.

- Transversal actions on the resilient corridor. A set of actions and technologies are foreseen all along the corridor with the aim to create new connections among the Hubs and toward the entire city and for starting new circular approaches between the Hubs and the city based on making the territory regenerative with relation to energy flows, people flows, resilience, sustainability, energy efficiency.

The model intends resilient corridors as physical spaces, framed by the presence of natural or artificial infrastructures (such as streets, railways, rivers, etc.), connecting urban and peri-urban areas. Inside resilient corridors several innovation hubs can be identified: spaces where existing activities are ongoing (e.g. innovative districts, cultural activities, bottom up processes, etc.) and where testing the implementation of innovative actions aiming to close resources loops (e.g. water, food, waste, energy, etc.).

The connection among innovation hubs can support the creation of new value chains strengthening relations among actions, actors, spaces and resources, that act as an engine to regenerate and improve the mutual exchange between different areas of the cities according to a systemic approach.

The resilient corridor is intended as a primary pilot area of intervention where actions (social, technological, environmental) can be applied on specific areas named innovation hubs (Fig. 2).

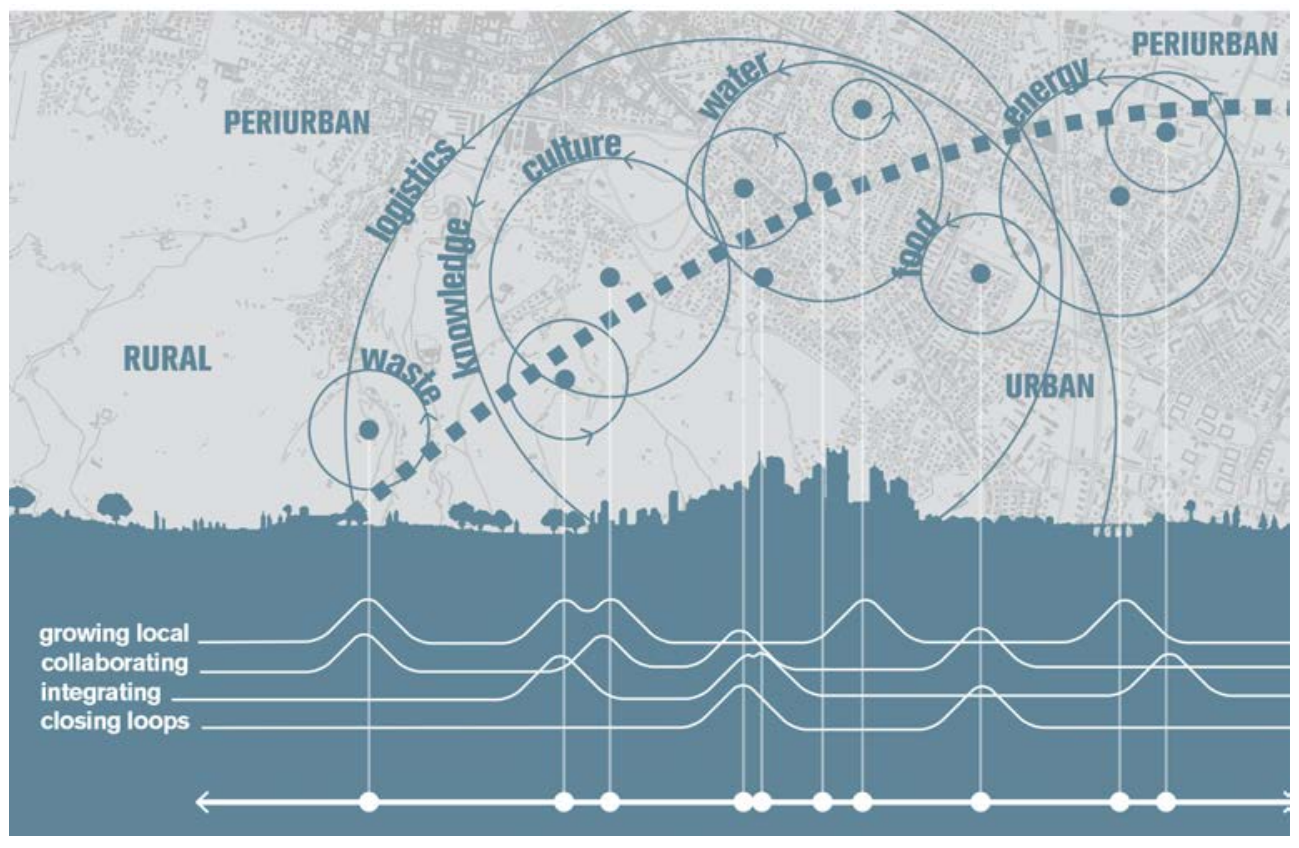

Figure 2: Resilient corridors and innovation hubs. 
The single activities can be discussed with the local ecosystem of stakeholders.

The corridor concept allows the development of designs that engage issues connected to the territory.

Re-use of public spaces and building regeneration represent a key action to reduce land consumption and improve the quality of built environment while hosting ecosystem services as an integral part of the circular development model including:

- reduction of materials use, of new land and buildings;

- reuse and shared use of existing goods with new functions;

- maintenance of existing good ensuring longer life;

- energy recovery;

- re-use of specific local knowledge for valorising the differences in the territories.

\section{IMPACT ANALYSIS AND KEY PERFORMANCE INDICATORS}

A number of impacts grouped into layers are the result of the model application. The model uses complementary qualitative and quantitative methods (participants observation, informal, interviews, focus groups and mini surveys) in order to delineate, explain, and understand the complex nature of circular urban system approach; to grasp highly interactive social situations - considering the participation of vulnerable groups (minorities, elderly and socially marginalized populations, understanding people's values, motivations and behaviours; and to assess the project's impact on its various audiences. Thus, different layers of impacts and related performance indicators can be identified:

- impacts linked with the model application in urban context which leads to policydriven indicators;

- impacts linked with the application of actions leading to innovation -driven indicators;

- impacts related with people involvement and participatory approaches leading to social-driven indicators;

- impacts linked with the success of the process.

According to the purpose of this paper, an example of indicators are provided in Table 1.

\section{CONCLUSIONS AND FOLLOWING DEVELOPMENT}

This position paper represents a first work toward an innovative and systemic model for regenerative cities aiming to include several steps. The paper describes the methodological backbone of the study and the implementation model as well as the preliminary application fields according to the general structure. Its main objectives are strictly aligned with the 17 Sustainable Development Goals [24] and mainly with the urban related one, addressing the following tasks: "support positive economic, social and environmental links between urban, peri-urban and rural areas by strengthening national and regional development planning; by 2020, substantially increase the number of cities and human settlements adopting and implementing integrated policies and plans towards inclusion, resource efficiency, mitigation and adaptation to climate change, resilience to disasters, and develop and implement".

The further development of the study may include in the future:

- a roadmap for regenerative and circular cities and the structure of an integrated management plan for resilient corridors;

- a guideline for closing resource loops in specific demo cases; 
Table 1: Example of indicators.

\begin{tabular}{|c|c|}
\hline Expected impacts & Indicators \\
\hline \multirow{5}{*}{$\begin{array}{l}\text { Measurable increase of the } \\
\text { regenerative capacity of } \\
\text { urban and peri-urban areas }\end{array}$} & $\begin{array}{l}\text { Number of projects including urban and peri-urban areas } \\
\text { proposed by communities }\end{array}$ \\
\hline & $\begin{array}{l}\text { Decreasing \% of carbon footprint of the regenerative corridor } \\
\left(\mathrm{CO}_{2} \mathrm{e} / \text { cap }\right)\end{array}$ \\
\hline & Increasing \% of re-use and recycling (spaces and resources) \\
\hline & $\begin{array}{l}\text { Number of projects from communities working on re-use and } \\
\text { recycle }\end{array}$ \\
\hline & Decreasing \% of land use around regenerative corridors \\
\hline \multirow{3}{*}{$\begin{array}{l}\text { New cooperation } \\
\text { opportunities in local } \\
\text { governance innovation to } \\
\text { response to stakeholders } \\
\text { needs }\end{array}$} & $\begin{array}{l}\text { Increasing in \% of active and visible participation of women } \\
\text { and ethnic minorities in initiatives and activities }\end{array}$ \\
\hline & $\begin{array}{l}\text { Number of multi-actor (PA/citizenship/suppliers) agreements } \\
\text { for the management of corridors as common goods }\end{array}$ \\
\hline & Number of collective initiatives under the agreement \\
\hline \multirow{3}{*}{$\begin{array}{l}\text { Boost creativity and } \\
\text { entrepreneurship related to } \\
\text { circularity and } \\
\text { regenerative processes; } \\
\text { Promoting local growth }\end{array}$} & $\begin{array}{l}\text { Increasing in \% the number of short-cut circular ancillary } \\
\text { business along the corridors }\end{array}$ \\
\hline & $\begin{array}{l}\text { Increasing in \% of real estate value and revenu } \\
\text { demonstration areas }\end{array}$ \\
\hline & $\begin{array}{l}\text { Number of initiatives promoted by local association about } \\
\text { circularity of resource flows }\end{array}$ \\
\hline \multirow{5}{*}{$\begin{array}{l}\text { Measurable reduction of } \\
\text { materials, natural resource } \\
\text { consumption and } \\
\text { environmental footprint in } \\
\text { urban and peri-urban areas }\end{array}$} & $\begin{array}{l}\text { Number of circular experiments along regenerative corridors } \\
\text { promoted by living labs (LLs) }\end{array}$ \\
\hline & $\begin{array}{l}\% \text { of reduction of resources consumption along the corridors } \\
\text { during experimental phases }\end{array}$ \\
\hline & $\begin{array}{l}\% \text { of reduction of resources consumption after pilot phase } \\
\text { completion }\end{array}$ \\
\hline & $\begin{array}{l}\text { Decreasing \% of carbon footprint of the regenerative corridor } \\
\left(\mathrm{CO}_{2} \mathrm{e} / \text { cap }\right)\end{array}$ \\
\hline & $\begin{array}{l}\text { Increasing in \% of new data about circularity and regenerative } \\
\text { capacity }\end{array}$ \\
\hline
\end{tabular}

- a guideline for citizen participation and co-design inside innovation hubs;

- a set of enabling technologies to boost the process;

- a more detailed set of impacts and related key performance indicators emerged and monitored during the experimental process.

Once completed and successfully tested, the model can bring regenerative cities to benefit the environment and natural ecosystems; drive the local economy; improve neighbourhood cohesion and health; increase their own resilience and enhance participatory decision-making.

Nonetheless, a number of barriers are embedded in the current political, financial and social institutional framework can be identified: the biggest obstacle is often represented by 
the limited political horizon characterizing the public administration, however also the lack of systematic framework for stakeholders engagement to build effective public participatory process can become a barrier to achieve a wide consensus and an acceptable level of public awareness around the main scope of the project. A systematic analysis of potential barriers and obstacles certainly represents the very next step of the study in order to set adequate guidelines for supporting the process at political and societal level.

\section{REFERENCES}

[1] Batty, M., Axhausen, K.W., Giannotti, F., Pozdnoukhov, A., Bazzani, A. \& Wachowicz, M., Smart cities of the future. The European Physical Journal, 214, pp. 481-518, 2012.

[2] Bonomi, A. \& Masiero, R., Dalla Smart City alla Smart Land, Marsilio, 2014.

[3] Hajer, M. \& Dassen, T., Visualizing the Challenge for 21st Century Urbanism, naio10 Publisher/PBL Publishers: Amsterdam, 2014.

[4] Secchi, B., La città dei ricchi e la città dei poveri, Laterza, 2013.

[5] Espon, Territorial Dimensions of the Europe 2020 Strategy, 2013. www.espon.eu/ topics-policy/publications/evidence-briefs/espon-atlas-territorial-dimensions-europe2020-strategy. Accessed on: 15 Jul. 2018.

[6] Directorate-General for Internal Policies, European Parliament, Mapping smart cities in the EU, 2014. www.europarl.europa.eu/RegData/etudes/etudes/join/2014/507480/ IPOL-ITRE_ET(2014)507480_EN.pdf. Accessed on: 15 Jul. 2018.

[7] European Environment Agency, Urban adaptation to climate change in Europe, 2012. www.eea.europa.eu/publications/urban-adaptation-to-climate-change. Accessed on: 15 Jul. 2018.

[8] IPCC, Climate Change: Action, trends and implications for business. The IPCC's Fifth Assessment Report. www.bmz.de/en/publications/type_of_publication/ weitere_materialien/Science_Report_Briefing_WEB_EN.pdf. Accessed on: $15 \mathrm{Jul}$. 2018.

[9] McBean, G., Climate change: Global risks, challenges and decisions. Eos, Transactions American Geophysical Union, 93(18), p. 182, 2012.

DOI: 10.1029/2012EO180011

[10] Parlamento Europeo, Direttiva 2010/31/UE sulla prestazione energetica nell'edilizia, 2010. http://eur-lex.europa.eu/legal-content/IT/TXT/?qid=1494156063818\&uri= CELEX:32010L0031. Accessed on: 15 Jul. 2018.

[11] Wolfram, M., Deconstructing smart cities: An intertextual reading of concepts and practices for integrated urban and ICT development. Real Corps, pp. 171-180, 2012.

[12] Matzarakis, A., Georgiadis, T. \& Rossi, F., Thermal bioclimatic analysis for Europe and Italy. Nuovo Cimento Della Societa Italiana Di Fisica C, 30(6), pp. 623-632, 2007. DOI: $10.1393 / \mathrm{ncc} / \mathrm{i} 2007-10268-0$.

[13] Santamouris, M., Innovating to zero the building sector in Europe: Minimising the

[13] energy consumption, eradication of the energy poverty and mitigating the local climate change. Solar Energy, 128, pp. 61-94. DOI 10.1016/j.solener.2016.01.021.

[14] Salop Steven, C., Monopolistic competition with outside goods. The Bell Journal of Economics, 10(1), pp. 141-156, 1979.

[15] Hotelling, H., Stability in competition. The Economic Journal, 39(153), pp. 41-57, 1929.

[16] Murray, A., Skene, K. \& Haynes, K., The circular economy: an interdisciplinary exploration of the concept and application in a global context. Journal of Business Ethics, 140(3), pp. 369-380, 2017. DOI: 10.1007/s10551-015-2693-2. 
[17] Kennedy, C., Cuddihy, J. \& Engel-Yan, J., The changing metabolism of cities. Journal of Industrial Ecology, 11(2), pp. 43-59, 2008. DOI: 10.1162/jie.2007.1107.

[18] Zaman, A. \& Lehmann, S., The zero-waste index: A performance measurement tool for waste management systems in a 'zero waste city'. Journal of Cleaner Production, 50, pp.123-132, 2013. DOI: 10.1016/j.jclepro.2012.11.041.

[19] Kirchherr, J., Reike, D. \& Hekkert, M., Conceptualizing the circular economy: An analysis of 114 definitions. Resources, Conservation and Recycling, 127, pp. 221232, 2017.

[20] UN Habitat, The City We Need 2.0, World Urban Campaign. www.worldurbancampaign.org/resources. Accessed on: 15 Jul. 2018.

[21] UN Habitat III, New Urban Agenda. http://habitat3.org/wp-content/uploads/NUAEnglish.pdf. Accessed on: 15 Jul. 2018.

[22] European Commission, Closing the loop: An EU action plan for the Circular Economy COM/2015/0614. www.eea.europa.eu/policy-documents/com-2015-0614final. Accessed on: 15 Jul. 2018.

[23] Vernay, A.B.H., Circular urban systems: moving towards systems integration. Doctoral dissertation, TU Delft, Delft University of Technology, 2013.

[24] United Nations, sustainable development goals. www.un.org/sustainabledevelopment/sustainable-development-goals/. Accessed on: 15 Jul. 2018. 